2

3

4

\title{
Edge-Rich Black Phosphorous for Photocatalytic Nitrogen Fixation
}

\author{
Shi Bian, ${ }^{\dagger, \#}$ Min Wen, ${ }^{\dagger, \#}$ Jiahong Wang, ${ }^{\dagger, t}$ Na Yang, ${ }^{\dagger}$ Paul K Chu, Xue-Feng Y ${ }^{\dagger, *}$
}

${ }^{\dagger}$ Shenzhen Engineering Center for the Fabrication of Two-dimensional Atomic Crystals, Shenzhen 518055, P. R. China, Shenzhen Institutes of Advanced Technology, Chinese Academy of Sciences, Shenzhen 518055, P. R. China

¥ Department of Physics, Department of Materials Science and Engineering, and Department of Biomedical Engineering, City University of Hong Kong, Hong Kong, P. R. China

Email: xf.yu@siat.ac.cn

List of the materials supplied

Experimental Procedures:Chemicals, Synthesis,Characterizations,Photocatalysisand mechanism studies

Results and Discussion:

Figure S1. Dynamic light scattering spectra and zeta potentials of eBP NFs

Figure S2. TEM image of eBP NFs

Figure S3. Electron diffraction spectra of eBP NFs

Figure S4. Characterization of conventional BP NFs

Figure S5. TEM-EDS images and XPS spectra of eBP NFs

Figure S6. UV-Vis-NIR absorption spectra of eBP NFs in stability experiments

Figure S7. Calibration curve of Nessler's tests

Figure S8.TA decay of eBP NFs in Ar saturated water

Figure S9. Additional results for time profiles of normalized TA of eBP NFs

Table $\mathrm{S} 1$. The reported photocatalytic $\mathrm{N}_{2}$ fixation systems 


\section{Experimental Procedures}

\subsection{Chemicals}

Red phosphorus(RP, 99.999\%), sodium sulfite $\left(\mathrm{Na}_{2} \mathrm{SO}_{3}, 99.98 \%\right)$,sodium sulfide hydrate $\left(\mathrm{Na}_{2} \mathrm{~S} \cdot 9 \mathrm{H}_{2} \mathrm{O}, 99.98 \%\right)$, and zinc chloride $\left(\mathrm{ZnCl}_{2}, 99.98 \%\right)$ were purchased from Alfa Aesar.N-methylpyrrolidone (NMP, $99.5 \%$, anhydrous), ethanol, potassium hydroxide $(\mathrm{KOH})$, sodium hydroxide $(\mathrm{NaOH})$, and hydrochloric acid $(\mathrm{HCl})$ were bought from AladdinReagents.(2-Bromoethyl)-benzene were bought fromEnergy Chemical. Ultrapure water with a resistivity of $18.2 \mathrm{M} \Omega \cdot \mathrm{cm}$ was used in the experiments and all the chemicals were used without further purification.

\subsection{Synthesis}

\subsubsection{Synthesis of bulkblack phosphorus(BP)powders}

The bulk BP powders were prepared by a high-energy ball milling-method with RetschEmax.In brief, thered phosphorus powder and steel balls were put in a $50 \mathrm{~cm}^{3}$ steel capsule with a ball to powder ratio of 30:1.The high-energy ball-milling process was carried out in an inert atmosphere (argon) for $7 \mathrm{~h}$ at a rotation speed of 1500 $\mathrm{r} / \mathrm{min}$. The bulk BP powders were stored in a glove box for further use.

\subsubsection{Synthesis of edge-richBP nanoflakes (eBP NFs)}

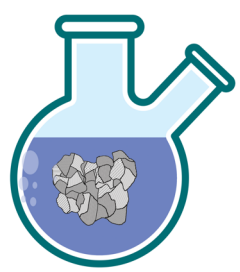

Chemical Etching

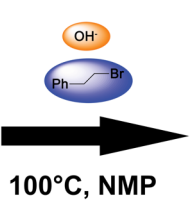

Scheme S1. Preparation procedure of eBP NFs

The bulk BP powders (25 mg, $0.8 \mathrm{mmol}$ ) and (2-bromoethyl)-benzene $(2-\mathrm{BrB})(147.2 \mathrm{mg}, 0.8 \mathrm{mmol})$ were dispersed with NMP $(10 \mathrm{~mL})$ in a Schlenk flask in a glove box under an inert atmosphere (argon). The Schlenk flask was then taken out and $2 \mathrm{mmol}$ of $\mathrm{KOH}$ in $2 \mathrm{ml}$ of distilled water was introduced to the Schlenk flask by the Schlenk line techniques. The mixture was stirred for $3 \mathrm{~h}$ at $100{ }^{\circ} \mathrm{C}$ andcentrifuged at $13,000 \mathrm{r} / \mathrm{min}$ for $10 \mathrm{~min}$. The solid was washed with water, ethanol,N,N-dimethylformamide (DMF), and NMPand dispersed in water (NMP or ethanol can also be used depending on the applications). The supernatant was finally collected by centrifugation at $7000 \mathrm{r} / \mathrm{min}$ for 10 minsto form the solution of eBP NFs. 


\subsection{Characterization}

X-ray diffraction (XRD) was performedon the Bruker D8 advance X-ray diffractometer using $\mathrm{Cu} \mathrm{K}_{\alpha}$ radiation $(\lambda=0.15418 \mathrm{~nm})$ and the Raman scattering spectra were acquired at room temperature on a Horiba Jobin-Yvon Lab Ram HR VIS high-resolution confocal Raman microscope with a $633 \mathrm{~nm}$ laser as the excitation source.Scanning electron microscopy (SEM) was conducted on the Zeiss Supra 55 high-resolution field-emission scanning electron microscope at $5.0 \mathrm{kV}$ accelerating voltage and the element maps were obtained at $15.0 \mathrm{kV}$. The transmission electron microscopy (TEM) and high-angle annular dark-field scanning transmission electron microscopy (HAADF-STEM) images were obtained on a field-emission transmission electron microscope (JEOL JEM 3200Fs) at $300 \mathrm{kV}$. The single-sheet elemental maps were acquired on the JEOL JEM 3200Fsat $300 \mathrm{kV}$ equipped with energy dispersive X-ray spectroscopy (EDS).X-ray photoelectron spectroscopy (XPS) was conducted on the Thermo Fisher Escalab 250Xiusing monochromatic $\mathrm{Al} \mathrm{K}_{\alpha}$ radiation and atomic force microscopy was carried out on the Bruker MultiMode 8.The UV-Vis-NIR diffuse reflectance spectra (DRS) were acquired on theAgilent Cary 7000 and the photoelectrochemicalproperties were determined on the CHI-760E workstation (China, Shanghai).

\subsection{Photocatalysis and mechanism studies}

\subsubsection{Photocatalytic $N_{2}$ reduction}

The eBP NFs $(\sim 0.5 \mathrm{mg})$ were dispersed in ultrapure water in a Schlenk tube. After a certain amount of $\mathrm{Na}_{2} \mathrm{SO}_{3}$ and $\mathrm{Na}_{2} \mathrm{~S} \cdot 9 \mathrm{H}_{2} \mathrm{O}$ was added to the eBP NFs solution, the mixture was saturated with nitrogen for 30 minutes. The light source was a LED lamp $(\lambda=420 \mathrm{~nm})$ equipped with an agitator and cooling apparatus. After irradiation for a certain period of time, the liquid was taken out to determine the amount of ammonium.

\subsubsection{Detection of ammonium}

The amount of ammonium was determined with the typical Nessler's reagent. In order to reduce the interference from other ions, the residual $\mathrm{SO}_{3}{ }^{2-}$ and $\mathrm{S}^{2-}$ in the mixture were removed by excess $\mathrm{ZnCl}_{2}$ and after centrifugation, the supernatant reacted with excess $\mathrm{NaOH}$ to remove the redundant $\mathrm{Zn}^{2+}$. The $\mathrm{pH}$ of the supernatant was adjusted to neutral with $\mathrm{HCl}$. According to recent studies, alcohol would react with the Nessler's reagent to undermine the accuracy of the Nessler's test. ${ }^{1}$ Therefore, $\mathrm{SO}_{3}{ }^{2-} / \mathrm{S}^{2-}$ was selected as the hole scavenger which could be removed 
1 easily from the solution using the procedures stated above. The trace amounts of the $2 \mathrm{SO}_{3}{ }^{2-} / \mathrm{S}^{2-}$ and $\mathrm{Zn}^{2+}$ ions left in the solution did not impact the Nessler's test as 3 confirmed by previous studies as well as the control experiments in this study (Figure 4 3a). Finally, the neutral mixture reacted with Nessler's reagent to form a 5 yellow-orange solution and the absorbance at $420 \mathrm{~nm}$ was monitored to calculate the 6 amount of ammonium.

7 8

\subsubsection{Photoelectrochemical experiments}

The photoelectrochemical experiments were carried out using atypical three-electrode setup in which the ITO glass pasted with the samplewas the working electrode, saturated calomel electrode (SCE) was the reference electrode, and platinum sheet was the counter electrode. $\mathrm{Na}_{2} \mathrm{SO}_{4}(0.1 \mathrm{M})$ was used as the electrolyte. Before the test, the electrolyte was saturated with $\mathrm{N}_{2}$ or Ar for 30 minutes and the experiments were conducted under $\mathrm{N}_{2}$ or Ar.

\subsubsection{Transient absorption spectroscopy}

The transient absorption spectra were acquired from eBP NFs on the Helios fem to second transient absorption spectrometer (Ultrafast Systems, LLC). A $400 \mathrm{~nm}$ pump pulse was generated by an optical parametric amplifier (OPerA Solo, Coherent) from the original laser with a wavelength of $800 \mathrm{~nm}(100 \mathrm{fs}, 1 \mathrm{kHz}$ repetition rate, Astrella-Tunable-V-F-1k, Coherent). A broad white light probe with a continuous spectrum was generated with a sapphire crystal. 3 
1

2

3

4 5

6

\section{Supplementary Figures}

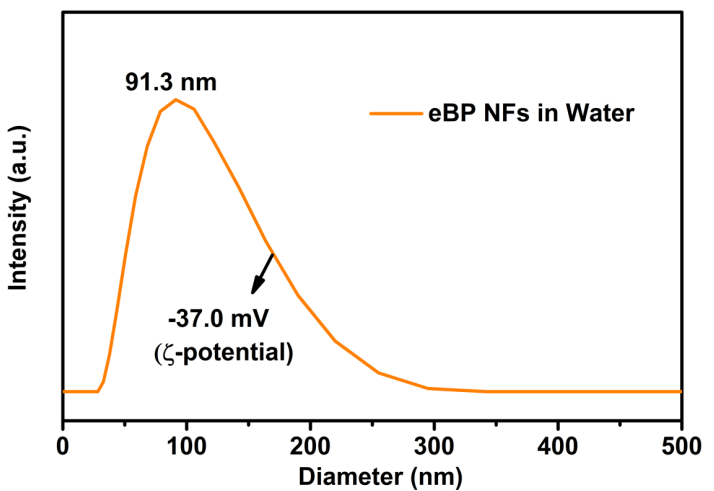

Figure S1. Dynamic light scattering (DLS) spectra and zeta potentials of eBP NFs in water and ethanol.

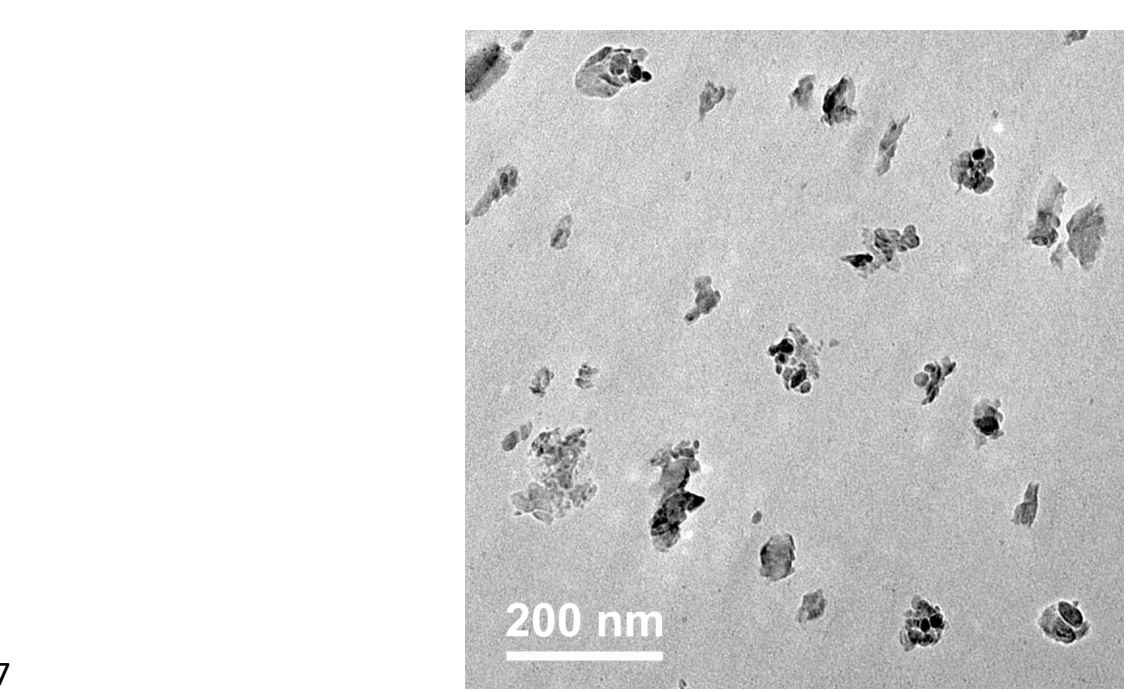

Figure S2.TEM image of eBP NFs.

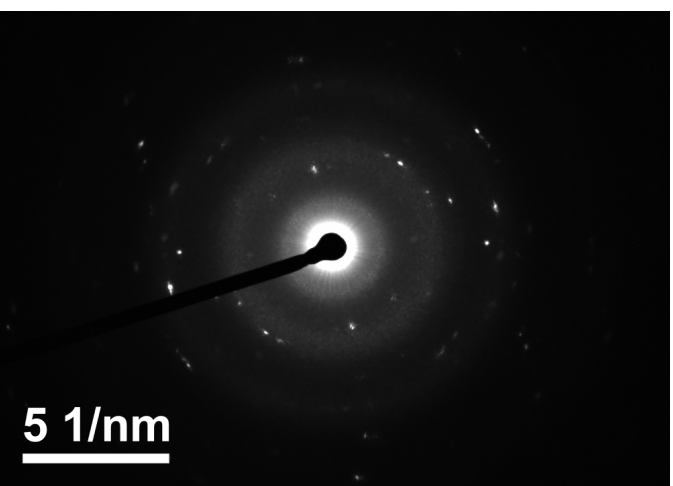

Figure S3. Electron diffraction spectra by TEM acquired from the eBP NFs in Figure $1 \mathrm{c}$. 
a
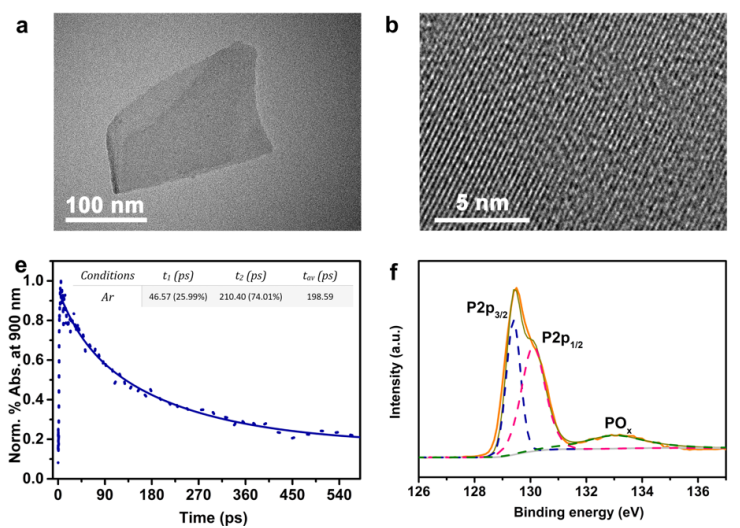
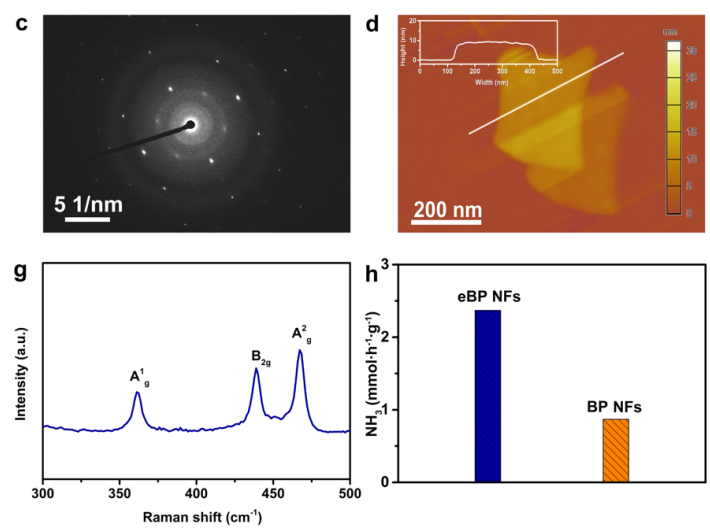

Figure S4. (a) TEM image of normal BP nanoflakes (BP NFs) [More details about the synthesis and characterization of BP NFs in our previous publication]; ${ }^{2}$ (b) HRTEM image of the BP NFs in (a); (c) Electron diffraction spectra by TEM obtained from the BP NFs in (a); (d) AFM image and line profiles of BP NFs; (e) Time profiles of normalized transient absorption of BP NFs at $900 \mathrm{~nm}$ in Ar; (f) P 2p XPS spectra of BP NFs; (g) Raman scattering spectrum of BP NFs; (h) Photocatalytic ammonia production rates using eBP NFs and BP NFs as the catalyst (Experiments performed under the same conditions).

a

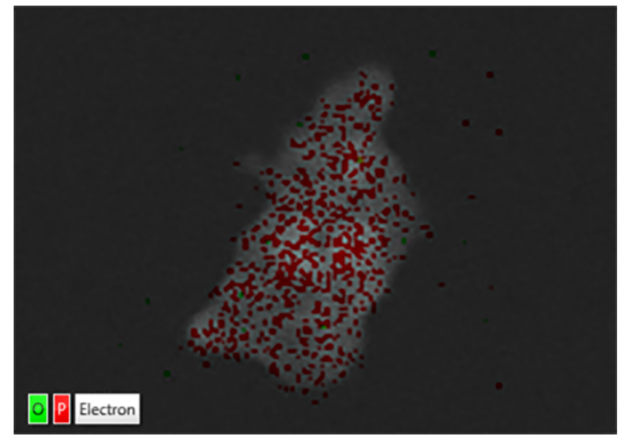

EDS

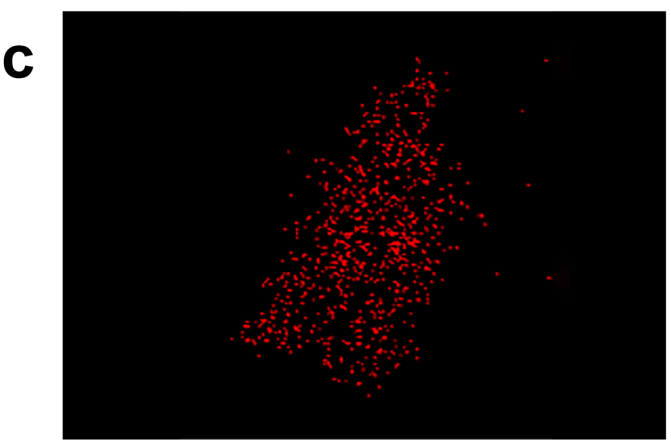

P Ka1

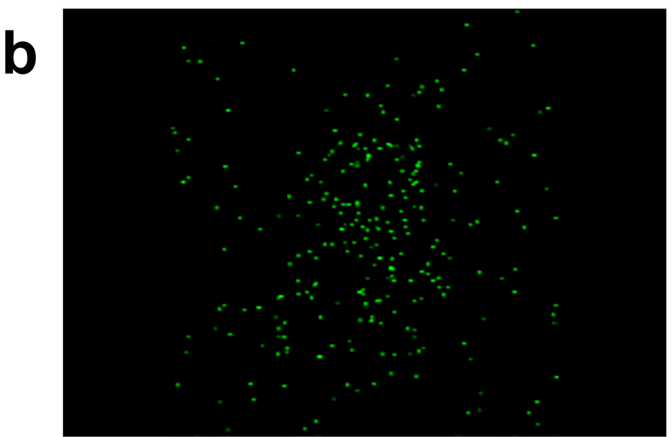

$\mathrm{OKa1}$

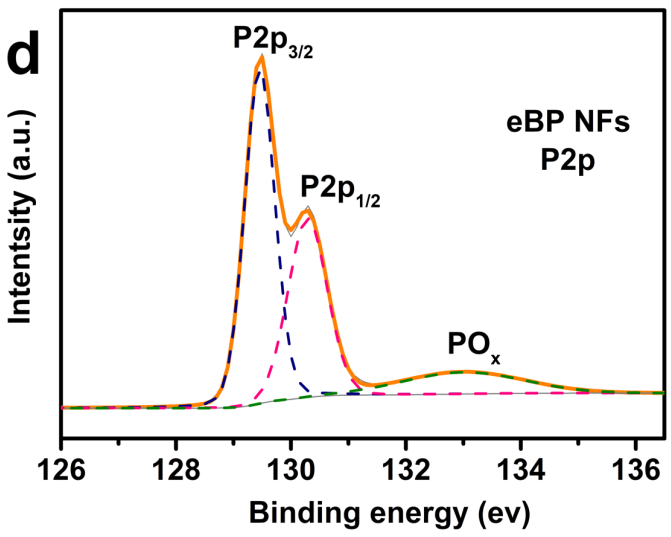

Figure S5. (a) TEM-EDS mapping image of eBP NFs; (b) TEM-EDS mapping result of oxygen element on eBP NFs; (c) TEM-EDS mapping result of phosphorous element on eBP NFs; (d) P 2p XPS spectra of eBP NFs. 

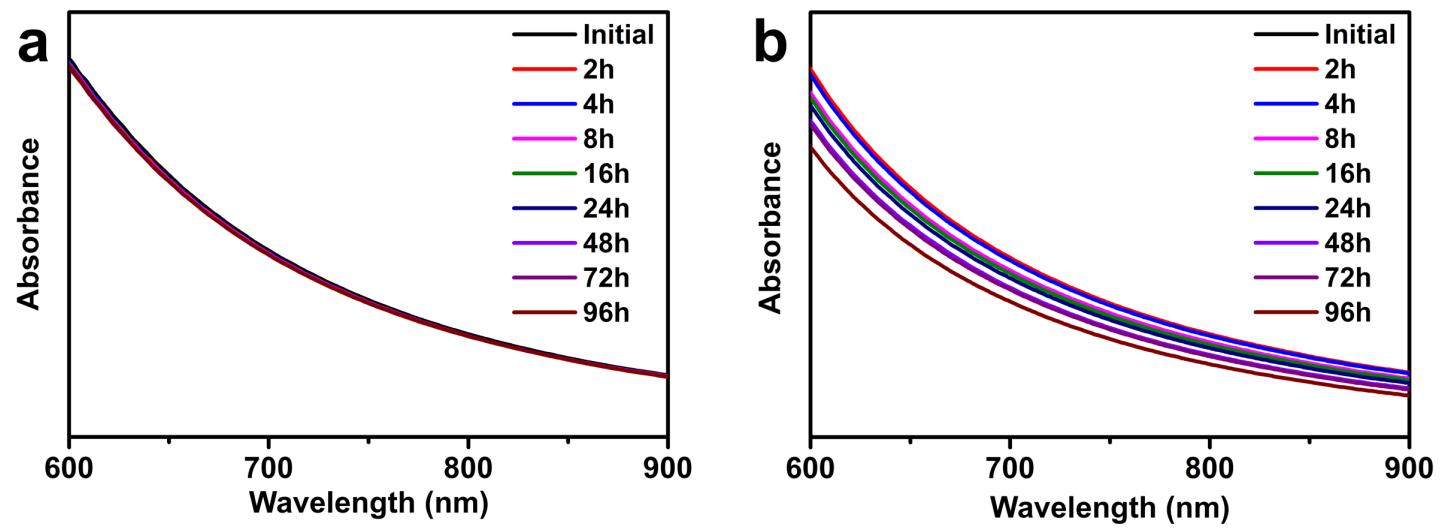

2 Figure S6. (a) UV-Vis-NIR absorption spectra of eBP NFs in the aqueous 3 solutionduring the stability tests without light;(b)UV-Vis absorption spectra of eBP $4 \quad$ NFs in the aqueous solution during the stability test under irradiation by LED lamps 5 (about $420 \mathrm{~nm}$ ).

6
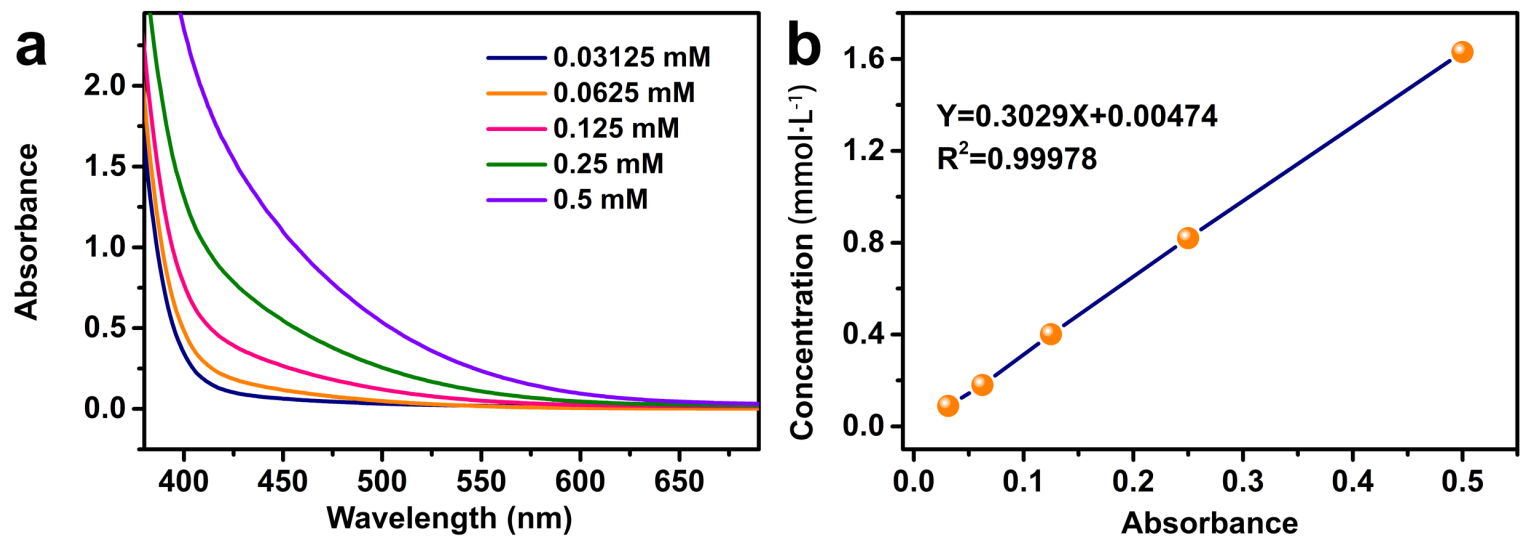

7

Figure S7. (a) UV-Vis absorption spectraof the standard ammonia solutions with 9 different concentration mixed with Nessler's reagent, which is forpreparing the 10 calibration curve of Nessler's tests; (b) Calibration curve of Nessler's tests (UV-vis absorbance on $420 \mathrm{~nm}$ versus ammonia concentration).

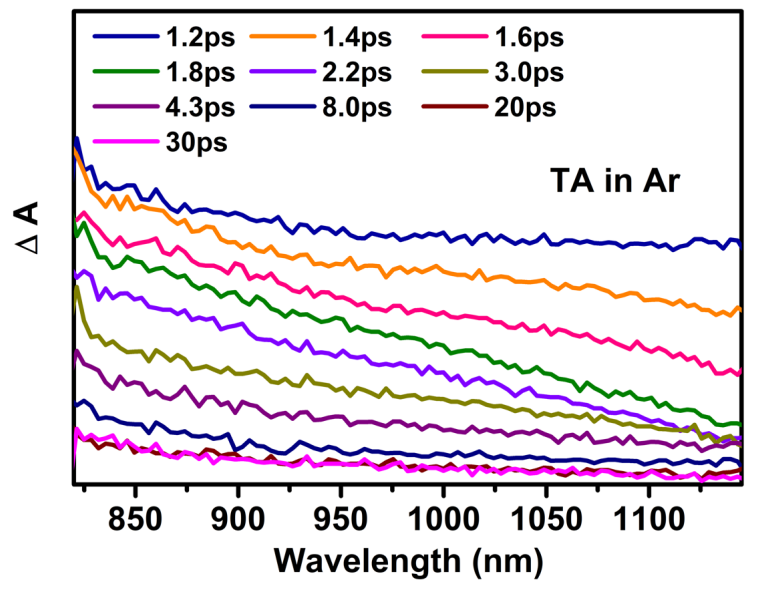

Figure S8.TA decay of eBP NFs in Ar saturated water. 

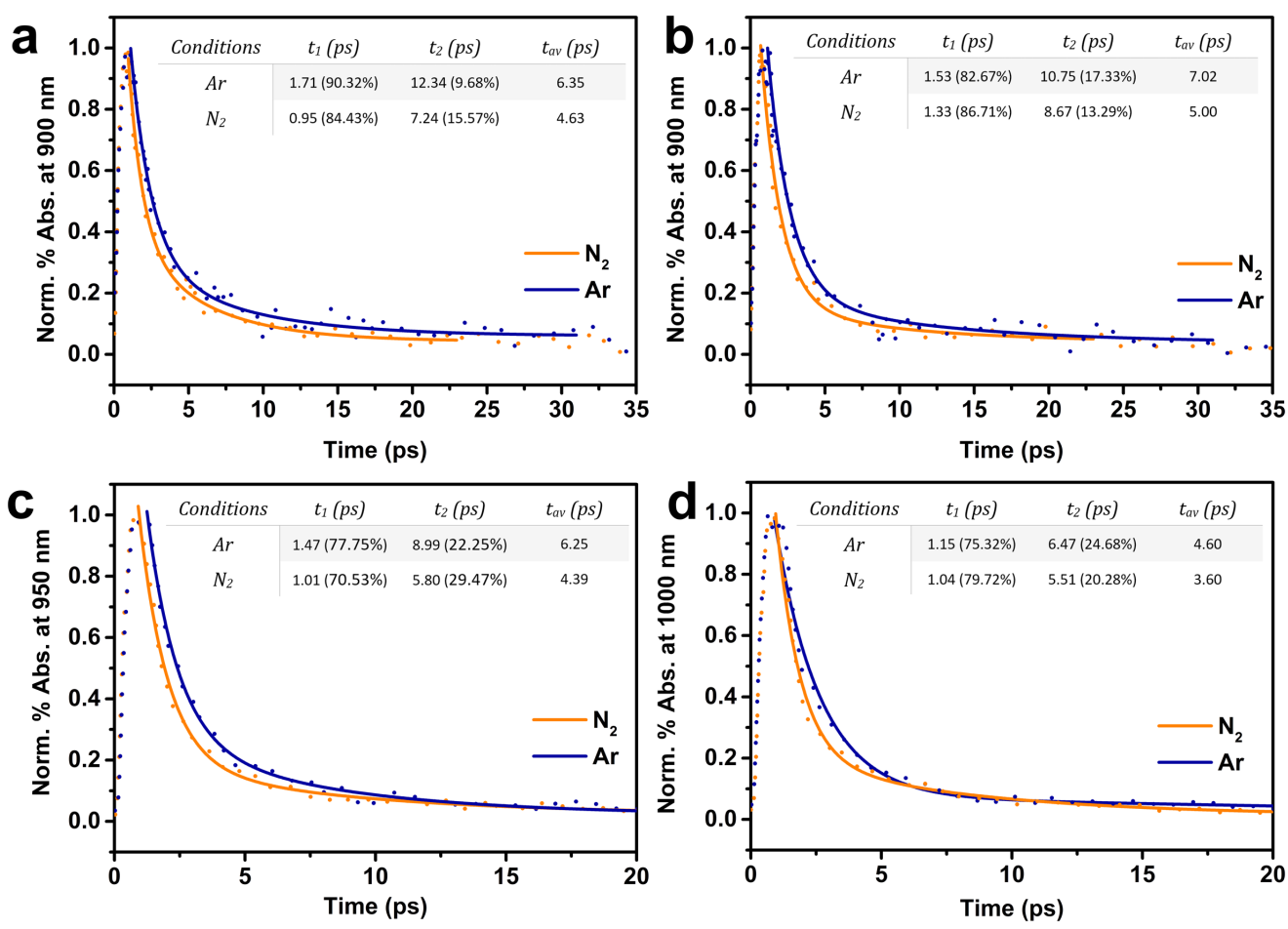

1 


\begin{tabular}{|c|c|c|c|c|}
\hline Catalysts & Scavengers & $\begin{array}{c}\mathrm{NH}_{3} \text { yield } \\
\left(\mathrm{mmol}^{\prime} \cdot \mathrm{h}^{-1} \cdot \mathrm{g}_{\mathrm{ca}}\right. \\
\left.\mathrm{t}^{-1}\right)\end{array}$ & Test methods & Refs. \\
\hline $\mathrm{K} / \mathrm{Ru} / \mathrm{TiO}_{2-\mathrm{x}} \mathrm{H}_{\mathrm{x}}$ & No & 0.495 & Nessler's reagent & 3 \\
\hline $\mathrm{Au} / \mathrm{TiO}_{2}-\mathrm{OVs}$ & Methanol & 0.786 & $\begin{array}{c}\text { Indophenol blue } \\
\text { method }\end{array}$ & 4 \\
\hline $\mathrm{Fe}_{2} \mathrm{O}_{3}$ & Ethanol & 1.365 & Nessler's reagent & 5 \\
\hline $\mathrm{Au} /$ end- $\mathrm{CeO}_{2}$ & Methanol & 0.114 & $\begin{array}{l}\text { Indophenol blue } \\
\text { method }\end{array}$ & 6 \\
\hline $\begin{array}{c}\mathrm{Mo}-\mathrm{W}_{18} \mathrm{O}_{49} \\
\text { nanowires }\end{array}$ & $\mathrm{Na}_{2} \mathrm{SO}_{3}$ & 0.196 & $\begin{array}{c}\text { Ion } \\
\text { chromatography/ } \\
\text { Nessler's reagent }\end{array}$ & 7 \\
\hline $\mathrm{MoS}_{2}$ & No & 0.325 & $\begin{array}{c}\text { Indophenol blue } \\
\text { method }\end{array}$ & 8 \\
\hline $\mathrm{Bi}_{5} \mathrm{O}_{7} \mathrm{Br}$ & No & 1.380 & Nessler's reagent & 9 \\
\hline $\mathrm{Cu} / g-\mathrm{C}_{3} \mathrm{~N}_{4}$ & Ethanol & 0.186 & Nessler's reagent & 10 \\
\hline $\mathrm{TiO}_{2} @ \mathrm{C} / g-\mathrm{C}_{3} \mathrm{~N}_{4}$ & Methanol & 0.251 & Nessler's reagent & 11 \\
\hline $\mathrm{Fe}_{0.05}-g-\mathrm{C}_{3} \mathrm{~N}_{4}$ & Ethanol & 0.3 & Nessler's reagent & 12 \\
\hline $\mathrm{KOH}$ treated $g-\mathrm{C}_{3} \mathrm{~N}_{4}$ & Methanol & 3.632 & Nessler's reagent & 13 \\
\hline $\mathrm{BP}_{0.05}-g-\mathrm{C}_{3} \mathrm{~N}_{4}$ & Methanol & 0.579 & Nessler's reagent & 14 \\
\hline eBP NFs & $\mathrm{Na}_{2} \mathrm{SO}_{3}$ & 2.37 & Nessler's reagent & $\begin{array}{l}\text { This } \\
\text { work }\end{array}$ \\
\hline
\end{tabular}

\section{References}

(1) Zhao, Y.; Shi, R.; Bian, X.; Zhou, C.; Zhao, Y.; Zhang, S.; Wu, F.; Waterhouse, G.I.N.; Wu, L-Z.; Tung, C-H.; Zhang, T. Ammonia Detection Methods in Photocatalytic and Electrocatalytic Experiments: How to Improve the Reliability of $\mathrm{NH}_{3}$ Production Rates? Adv. Sci. 2019, 6, 1802109.

(2) Wang, J.; Liu, D.; Huang, H.; Yang, N.; Yu, B.; Wen, M.; Wang, X.; Chu, P.K.; Yu, X-F. In-Plane Black Phosphorus/Dicobalt Phosphide Heterostructure for Efficient Electrocatalysis. Angew. Chem. 2018, 130, 2630-2634.

(3) Mao, C.; Yu, L.; Li, J.; Zhao, J.; Zhang, L. Energy-confined Solar Thermal Ammonia Synthesis with $\mathrm{K} / \mathrm{Ru} / \mathrm{TiO}_{2}-\mathrm{xHx}$. Appl. Catal. B Environ. 2018, 224, $612-620$. 
(4) Yang, J. H.; Guo, Y. Z.; Jiang, R. B.; Qin, F.; Zhang, H.; Lu, W. Z.; Wang, J. F.; Yu, J. C. High-Efficiency "Working-in-Tandem” Nitrogen Photofixation Achieved by Assembling Plasmonic Gold Nanocrystals on Ultrathin Titania Nanosheets. J. Am. Chem. Soc. 2018, 140, 8497-8508.

(5) Lashgari, M.; Zeinalkhani, P. Photocatalytic $\mathrm{N}_{2}$ Conversion to Ammonia Using Efficient Nanostructured Solar-energy-materials in Aqueous Media: A Novel Hydrogenation Strategy and Basic Understanding of the Phenomenon. Appl. Catal. A Gen. 2017, 529, 91-97.

(6) Jia, H.; Du, A.; Zhang, H.; Yang, J.; Jiang, R.; Wang, J.; Zhang, C.Y. Site-Selective Growth of Crystalline Ceria with Oxygen Vacancies on Gold Nanocrystals for Near-Infrared Nitrogen Photofixation. J. Am. Chem. Soc. 2019, 141, 5083-5086.

(7) Zhang, N.; Jalil, A.; Wu, D. X.; Chen, S.; Liu, Y. F.; Gao, C.; Ye, W.;Qi, Z.; Ju, H.; Wang, C.; Wu, X.; Song, L.; Zhu, J.; Xiong, Y. Refining Defect States in $\mathrm{W}_{18} \mathrm{O}_{49}$ by Mo Doping: A Strategy for Tuning $\mathrm{N}_{2}$ Activation towards Solar-Driven Nitrogen Fixation. J. Am. Chem. Soc. 2018, 140, 9434-9443.

(8) Sun, S.; Li, X.; Wang, W.; Zhang, L.; Sun, X. Photocatalytic Robust Solar Energy Reduction of Dinitrogen to Ammonia on Ultrathin $\mathrm{MoS}_{2}$. Appl. Catal. B Environ. 2017, 200, 323-329.

(9) Wang, S. Y.; Hai, X.; Ding, X.; Chang, K.; Xiang, Y. G.; Meng, X. G.;Yang, Z. X.; Chen, H.; Ye, J. H. Light-switchable Oxygen Vacancies in Ultrafine $\mathrm{Bi}_{5} \mathrm{O}_{7} \mathrm{Br}$ Nanotubes for Boosting Solar-driven Nitrogen Fixation in Pure Water. Adv. Mater. 2017, 29, 1701774.

(10) Huang, P.C.; Liu, W.; He, Z.H.; Xiao, C.; Yao, T.; Zou, Y. M.; Wang, C. M.; Qi, Z. M.; Tong, W.; Pan, B. C. Single Atom Accelerates Ammonia Photosynthesis. Sci. China Chem. 2018, 61, 1187-1196.

(11) Liu, Q. X.; Ai, L. H.; Jiang, J. MXene-derived $\mathrm{TiO}_{2} @ \mathrm{C} / g-\mathrm{C}_{3} \mathrm{~N}_{4}$ Heterojunctions for Highly Efficient Nitrogen Photofixation. J. Mater. Chem. A 2018, 6, 4102-4110.

(12) Hu, S. Z.; Chen, X.; Li, Q.; Li, F. Y.; Fan, Z. P.; Wang, H.; Wang, Y. J.; Zheng, B. $\mathrm{H}$; $\mathrm{Wu}, \mathrm{G} . \mathrm{Fe}^{3+}$ doping promoted $\mathrm{N}_{2}$ photofixation ability of honeycombed graphitic carbon nitride: The experimental and density functional theory simulation analysis. Appl. Catal. B Environ. 2017, 201, 58-69.

(13) Li, X. M.; Sun, X.; Zhang, L.; Sun, S. M.; Wang, W. Z. Efficient photocatalytic fixation of $\mathrm{N} 2$ by $\mathrm{KOH}$-treated $\mathrm{g}-\mathrm{C}_{3} \mathrm{~N}_{4}$. J. Mater. Chem. A 2018,6, 3005-3011.

(14) Qiu, P.; Xu, C.; Zhou, N.; Chen, H.; Jiang, F. Metal-free black phosphorus nanosheets-decorated graphitic carbon nitride nanosheets with C-P bonds for excellent photocatalytic nitrogen fixation. Appl. Catal. B Environ. 2018, 221, 27-35. 